\title{
Budismo Étnico em Perspectiva Comparada: Herança das Missões Japonesas no Brasi ${ }^{1}$ Ethnic Buddhism in comparative Perspective: The legacy of Japanese Missions in Brazil
}

Rafael Shoji*

Resumo: Após uma contextualização dos fluxos imigratórios entre o Japão e o Brasil, o artigo se concentrará na história e sociologia do Cristianismo entre os nipo-brasileiros. O Catolicismo brasileiro seguiu a tendência de subsistiu o Xintoísmo como religião de pertencimento nacional nas novas gerações nikkei, mas dados recentes sobre as religiões brasileiras no Japão indicam o crescimento do movimento pentecostal entre os decasségui. Seguindo uma perspectiva teórica dada pela economia das religióes e por redes sociais, buscam-se as principais explicações para o crescimento pentecostal. Ao final são apontadas algumas tendências referentes ao futuro do Cristianismo e de outras religiōes entre os brasileiros no Japão.

Palavras-chave: Cristianismo, Xintoísmo, Nikkei, imigração, redes sociais

Abstract: After having contextualized the immigration flows between Japan and Brazil, the article focusses on the history and sociology of Christianity among Japanese-Brazilians. As for the younger generations Brazilian Catholicism tended to substitute Shintoism in terms of a religious orientation fostering national identity. On the other hand, statistical data indicate that among decasségui, that is, Japanese descendants born Brazil who returned to Japan as foreign workers, Pentecostalism is on the rise. In order to explain the growing popularity of Pentecostalism, the article refers to approaches suggested by the economy of religion, including the social-network-theory. This conceptual basis even allows some speculations about the future of Christianity and other religions among the Brazilian foreign workers in Japan

Keywords: Christianity, Shintoism, nikkei, immigration, social networks

\footnotetext{
${ }^{1}$ Esse artigo é uma adaptação de $O$ Budismo Étnico na Religiosidade Nikkey no Brasil: Aspectos Históricos e Formas de Sobrevivência Social (SHOJI 2002).

* Mestre em Ciências da Religião pela Pontifícia Universidade Católica de São Paulo (2000), doutor em Ciência da Religião pela Universidade Leibniz, Hannover, Alemanha (2004) e pós-doutorado em Ciências da Religião na Pontifícia Universidade Católica de São Paulo (2006). Em 2006-2007 foi fellow pela Fundação Japão e pesquisador visitante no Instituto para Religião e Cultura da Universidade Nanzan (Nagóia).
} 


\section{Introdução}

Nesse ensaio busco analisar os atuais dilemas do Budismo nikkeis, apresentando os elementos conceituais e históricos envolvidos nas suas dificuldades de transmissão para os brasileiros ou novas geraçōes, apresentando comparaçôes resumidas com o Budismo étnico em outros países. No caso do Brasil, constata-se que o Budismo tradicional, que foi fruto das missões japonesas nos anos 60, vem se deparando com o dilema de adaptação ou extinção, com a progressiva integração cultural dos descendentes e o desaparecimento das primeiras geraçôes de imigrantes. Essa situação vem se desenvolvendo em quase todos os templos que não têm tido como prioridade uma abertura aos brasileiros, com o fechamento de muitos desses locais e diminuição do número de adeptos. ${ }^{2}$

Ainda existe uma expectativa da persistência da identidade nikkeis, por meio das gerações, na qual ainda se sustenta o envio de missionários japoneses, dedicados especialmente à assistência espiritual dos imigrantes e descendentes que continuam o culto aos antepassados. Essa estratégia supõe que uma religiosidade étnica pode ser simultânea a uma adaptação linguística e cultural, e que a identidade nikkeis vai se manter na diferenciação cultural e linguística com relação aos japoneses, e étnica, com relação aos brasileiros.

Além de desenvolver os aspectos conceituais do Budismo étnico nikkeis, pretendo colocar sua prática dentro de um contexto mais geral, fazendo comparações com o Budismo japonês original, com o Budismo étnico em outros países e, especialmente, apresentando uma contextualização do papel do Budismo para os nikkeis. No Brasil, o Budismo nikkeis apresenta um padrão de divisão ritualística com outras religiões, principalmente o Catolicismo. Essa prática budista vem ao encontro de uma convivência religiosa múltipla, frequentemente encontrada tanto no Brasil quanto no Japão. Apesar de estar em contraste com o ambiente de recepção na maioria dos países ocidentais, no Japão e no Brasil as religiões assumem constantemente aspectos funcionais e contextuais na vida dos adeptos. Simplificadamente, se no Japão o Xintoísmo é a religião que representa o pertencimento étnico e é usado nas cerimônias de nascimento, no caso, do Brasil o pertencimento nacional ocorreu por meio do batismo católico e, em muitos casos uma identidade nikkeis se deu por intermédio do Budismo. O Budismo tradicional, tanto no Japão quanto no Brasil, é reservado para os rituais funerários e culto aos antepassados da religiosidade familiar. Existem elementos históricos que permitem acompanhar a mudança na identidade étnica dos nikkeis e seu reflexo na sua prática religiosa atual, interpretada como uma estratégia de convivência e interação social, que é

\footnotetext{
${ }^{2}$ Cf. F.USARSKI, The Last Missionary to Leave the Temple Should Turn Off the Light, In: Japanese Journal of Religious Studies, pp. 39-59.
} 
influenciada por elementos brasileiros e japoneses, mas que também mantém uma distância de ambos.

\section{Budismo Étnico no Ocidente}

\section{Cultos aos Antepassados no Budismo Japonês}

Para que o conceito de Budismo étnico dos nikkeis possa ser aqui desenvolvido, é interessante contextualizar sua história dentro de uma discussão mais geral, tanto sobre o Budismo em países ocidentais como no que se refere às relaçôes entre etnicidade e religião. Apesar de o Budismo ser, de forma geral, muitas vezes descrito como uma das religiões universais, ao lado do Cristianismo e Islã, é necessária uma contextualização que dê conta da diversidade interna dos budistas e das particularidades do caso japonês. No caso do Budismo japonês, é possível identificar aspectos étnicos a partir da religiosidade popular japonesa, que combina elementos do Xintoísmo e da religiosidade familiar chinesa. De uma forma geral, os japoneses nunca incorporaram as doutrinas budistas da reencarnação e do sofrimento que estão presentes nas escrituras budistas mais antigas e que são o ponto de partida para muitos budistas ocidentais. Também os patriarcas japoneses são, em geral, as figuras mais valorizados pelas escolas, em contraste com Shakyamuni Buda. Em termos de prática religiosa, no Japão, o Budismo é associado principalmente ao culto aos antepassados que não se encontravam tão ligado ao Budismo antes de ele chegar ao Japão, além de conter devoções populares e elementos mágicos. Na separação ritual realizada com o Xintoísmo, o Budismo japonês se ocupa principalmente dos rituais funerários, dado que a morte tendia a ser um tabu tanto no Xintoísmo tradicional quanto no moderno. A maior parte dos japoneses tem funerais budistas, que são considerados um guia depois da morte.

Esse processo é finalizado depois de 49 dias após o falecimento, com a entrada do espírito do falecido no mundo dos antepassados. Anualmente, costuma-se realizar cerimônias budistas até o trigésimo terceiro ou quinquagésimo aniversário da morte. Em casa, os antepassados são geralmente cultuados através de um altar budista (butsudan), geralmente mantido pelo filho primogênito, no qual cada antepassado é representado com uma tabuleta de madeira com seu nome póstumo (ihai). Frequentemente são postas oferendas na forma de frutas, comida ou bebida no altar e muitos descendentes rezam e se comunicam com seus antepassados na frente do butsudan.

Dessa forma, o Budismo japonês é fortemente influenciado por uma tendência familiar e de culto aos antepassados ${ }^{3}$, o que também é reforçado pelas

\footnotetext{
${ }^{3}$ Alguns autores não só defendem que a religiosidade japonesa tem como base a família (cf. HORI, 1968, pp. 49-81), mas também que o Budismo tem sua organização baseada nesse conceito (cf. EARHART, 1997, pp.
} 
cerimônias budistas anuais mais populares, que, como no Xintoísmo e na cultura japonesa em geral, estão fortemente associadas às diferentes épocas e estaçôes do ano. Em contraposição às cerimônias realizadas na morte de um familiar, que são oficiadas no círculo privado, existem as cerimônias e festivais budistas de Obon e Ohigan. No Japão, o Obon ocorre normalmente em agosto, no verão, quando se crê popularmente que os ancestrais retornam do mundo dos antepassados para viver um curto período com seus descendentes. De forma semelhante é comemorado o Ohigan, realizado nos equinócios de primavera (março) e outono (setembro). Nessa época são realizados rituais budistas e são visitados e limpos os túmulos dos ancestrais. Em outros países asiáticos, fora o Japão, o culto aos antepassados é raramente relacionado e praticado no Budismo, embora as escolas japonesas tradicionais se refiram ao sutra chinês Urabon como justificação doutrinária.

Para alguns autores, o culto aos antepassados e o mundo depois da morte no caso japonês podem ser entendidos como algo independente e anterior à entrada do Budismo no Japão ${ }^{4}$, profundamente enraizado na mentalidade popular e em contradição com a doutrina budista. A família, na visão tradicional do culto aos antepassados, permanece unida inclusive após a morte. $\mathrm{O}$ mundo espiritual e dos antepassados não é somente amistoso, o que lembra novamente a influência que o Xintoísmo tem na visão de mundo japonesa. Faz parte da religiosidade popular, a ideia de que aqueles que tiveram uma morte violenta ou prematura, ou antepassados que se sentem desprezados pelo descuido ou falta de atenção dos descendentes, podem ter uma relação que prejudique os que vivem neste mundo. Por isso, fora as cerimônias tradicionais, em alguns grupos budistas também existem rituais e práticas que buscam eliminar essas potenciais causas do mal, principalmente em novos movimentos religiosos japoneses e nas escolas do Budismo esotérico japonês. De uma forma geral, a religiosidade japonesa tem um forte componente ritual associado à purificação, em detrimento de uma convicção pessoal e individual. Em alguns casos, essa tendência aparece descrita como um carma relacionado aos antepassados, principalmente nas novas religiões. Ainda que esse conceito seja uma motivação importante para a prática budista em alguns grupos, não parece existir fundamento doutrinário na história do Budismo que justifique essas ideias mais contemporâneas de carma. ${ }^{5}$

\footnotetext{
73-76). A família estaria expressa na organização dos templos e sacerdotes, praticamente substituindo um conceito de sangha tradicional, baseado no Vinaya.

${ }^{4}$ Cf. K.YANAGITA, About Our Ancestors.

${ }^{5}$ Para uma discussão geral sobre a reinterpretação do conceito de carma no Japão e em novos movimentos religiosos japoneses, consultar R.KISALA, Contemporary Karma: Interpretations of karma in Tenrikyo and Rissho Koseikai, In: Japanese Journal of Religions, pp.73-91.
} 


\section{Possibilidade de Sobrevivência do Budismo Étnico}

De uma forma geral, nos países ocidentais os estudos acadêmicos têm dividido os budistas em imigrantes e convertidos, que seriam distintas correntes em adaptação, com diferentes processos associados. O Budismo dos imigrantes teria como principal característica a preservação de uma identidade étnica, a partir de rituais e devoçóes específicas. As principais características do Budismo dos convertidos seriam uma interpretação mais racionalizada do Budismo e uma estreita associação com a meditação, tendo como perfil social característico pessoas educadas e das classes média e alta da sociedade. Essas duas correntes, apresentando um desenvolvimento relativamente independente e práticas autônomas, muitas vezes compartilham o mesmo espaço físico e, repetidamente, os mesmos líderes religiosos. Essas comunidades parecem apresentar, na maioria dos casos, somente uma pequena interação. Devido a essa situação e a partir de um estudo de campo do Budismo Theravada nos EUA, Numrich cunhou o termo "congregações paralelas", reafirmando a tendência de associar a prática religiosa ao elemento étnico. ${ }^{6}$

A tese das congregações paralelas consiste na afirmação da existência de dois grupos distintos de praticantes nos templos budistas, que utilizam reiteradas vezes o mesmo espaço físico e têm em comum até líderes religiosos, mas não apresentam uma intersecção devido a diferenças culturais, linguísticas e de prática religiosa. Um dos resultados dessa divisão é também o diferente referencial teórico existente para analisar cada uma dessas congregações, que, segundo Numrich, deve ser diferenciado para cada uma delas. Enquanto que o conceito e as teorias sociológicas sobre Novos Movimentos

Religiosos seriam úteis para se estudar os convertidos, o mesmo não pode ser dito em relação ao Budismo resultante da imigração. ${ }^{7}$

Nos EUA, pode-se dizer que essa divisão do Budismo tem gerado um intenso debate, associado principalmente à representatividade. ${ }^{8}$ Frequentemente afirma-se a preponderância dos estudos sobre um Budismo americano, em contraposição à contribuição dos imigrantes asiáticos para o Budismo. Excluídos os debates ideológicos e as disputas étnicas potenciais dessa divisão, é fato que o Budismo dos convertidos foi bem mais estudado e documentado nos EUA, utilizando principalmente o referencial dos Novos Movimentos Religiosos. Nos últimos anos, no entanto, tem ocorrido uma grande influência do conceito de etnia nas

\footnotetext{
${ }^{6}$ Cf. P.D.NUMRICH, Old Wisdom in the new world: Americanization in two immigrant Theravada Buddhist temples, pp. 63-79.

${ }^{7}$ Ibidem, p. 78

${ }^{8}$ Cf..R.FIELDS. Divided Dharma: White Buddhists, Ethnic Buddhists, and Racism. In: PREBISH, Charles S.; TANAKA, Kenneth K. (eds.). The Faces of Buddhist America. pp.196-206.
} 
abordagens sobre a adaptação do Budismo naquele país. ${ }^{9}$ Asai e Duncan mostram, por exemplo, que nos templos do Sôtô Zen, construídos antes dos anos 60, existe um padrão étnico e ritualístico que inexiste na compreensão dos convertidos ao Zen, o qual tem uma prática mais associada à meditação. ${ }^{10}$

A maioria dos estudos no continente americano, no entanto, ainda partem de uma correlação entre religiosidade étnica e Budismo mesmo em gerações mais avançadas de descendentes. Baseado na perda da consciência étnica nos descendentes de imigrantes, Mark Mullins propôs um modelo em três fases para o ciclo de vida das instituições religiosas fundadas por imigrantes, com base no Budismo japonês no Canadá. ${ }^{11}$ Na primeira fase, os integrantes da comunidade religiosa são somente os imigrantes, que criam um espaço cultural e religioso semelhante ao que existia em seu país de origem. $\mathrm{Na}$ falta de um centro cultural e de um grupo religioso na sua língua materna, é natural que os próprios imigrantes estabeleçam esses espaços de convivência étnica. Além da língua, um fator adicional para o estabelecimento dessas comunidades é que, em muitos casos, os imigrantes sofrem uma discriminação no país em que se estabelecem. Em uma segunda fase, com o surgimento de novas gerações de descendentes e uma maior aculturação do grupo imigrante, é importante que o grupo religioso comece a formar sacerdotes que sejam bilíngues, além de um trabalho de tradução dos principais textos e cerimônias, já que alguns integrantes começam a não ter fluência na língua dos antepassados. Com o tempo, ocorre a assimilação estrutural da comunidade de imigrante e descendentes, por meio de casamentos interétnicos, mobilidade geográfica e livre participação em entidades sem orientação ou ligação com a comunidade étnica, principalmente no que diz respeito à formação educacional.

Nesse ponto, a comunidade religiosa fundada pelos imigrantes entra em uma terceira fase, na qual se apresenta um grande dilema. Por um lado, a comunidade foi fundada tendo como orientação uma identidade étnica, sendo ainda controlada pelos imigrantes e tendo como tendência um certo conservadorismo. No entanto, a maior parte dos imigrantes originais já morreu, e as novas gerações estão totalmente integradas em outro país. O dilema é que essas instituições têm que redefinir seu propósito de existência social e dar um salto cultural, que representa

\footnotetext{
${ }^{9}$ Como um exemplo pode ser citado S.CHANDLER. Placing Palms Together: Religious and Cultural Dimensions of the Hsi Lai Temple Political Donations. In: WILLIAMS, Duncan Ryûken; QUEEN, Christopher S. (eds.). American Buddhism: pp.36-56. Nesse trabalho, desenvolve uma teoria de combinaçóes étnicas, sugerindo que as diferentes influências étnicas são determinantes para a autocompreensão do que é ser budista. ${ }^{10}$ Cf. S.ASAI; D.R. WILLIAMS. Japanese American Zen Temples: Cultural Identity and Economics. In: WILLIAMS, Duncan Ryûken; QUEEN, Christopher S. (eds.). American Buddhism, pp.20-35.

${ }^{11}$ Cf. M.MULLINS. The Life-Cycle of Ethnic Churches in Sociological Perspective. In: Japanese Journal of Religious Studies, pp.321-334.
} 
também a diferença entre as geraçôes, mas tendo ainda a preocupação de manter uma ortodoxia religiosa, muitas vezes confundida com a cultura imigrante pelos adeptos. Com base nesse dilema, prevê Mullins, excetuando casos de uma nova onda imigratória ou uma onda de preconceitos contra o grupo étnico, a comunidade religiosa fundada pelos imigrantes tem de se tornar multiétnica ou então corre o risco de desaparecer, por perder seu sentido social. De qualquer forma, o grupo religioso com uma única base étnica tenderia a acabar.

\section{Novas Gerações: Etnicidade como Interação Social}

Com sua ênfase nos antepassados, o Budismo japonês sempre fornece elementos que podem ser usados para uma identificação étnica por meio da valorização da origem e dos laços de parentesco. Por isso, um conceito de etnia não deixa de ser útil também para gerações posteriores, como argumentarei para o caso da colônia japonesa no Brasil. Nos EUA, principalmente após o abandono e a crítica das teorias assimilacionistas, o paradigma de etnicidade tem sido constantemente utilizado para estudar as comunidades de imigrantes e de descendentes, já que grande parte das pesquisas empíricas mostrou uma crescente consciência da identidade étnica, associadas a políticas de reafirmação de minorias. ${ }^{12}$

Ainda que o termo imigrante não possa ser atribuído aos descendentes, ainda existe uma religiosidade derivada de uma vivência como comunidade étnica, que pode ser prolongada por diversas gerações. Para que essa afirmação possa ser melhor desenvolvida em termos teóricos, é necessária uma reflexão sobre o conceito de etnia. Para os fins desse artigo, discutirei e utilizarei as propostas sobre etnia a partir do trabalho de Fredrik Barth. ${ }^{13}$ A partir de Barth e dos antropólogos que colaboram na sua linha teórica, surgiram diversas propostas para que o conceito pudesse ter um maior valor explicativo e refletisse melhor os dados empíricos das pesquisas antropológicas. Em resumo, ao invés de destacar os aspectos de raça ou cultura na identificação de grupos étnicos, a etnicidade é vista como uma forma de interação e organização social, na qual existe uma diferenciação entre os que são do grupo e os que não pertencem a ele. De uma maneira tradicional, um grupo étnico tinha sua formação justificada devido a um suposto isolamento devido a diferenças raciais, culturais ou linguísticas.

Visto como interação social, ainda que esses elementos continuem sendo importantes para a definição de um grupo étnico, o mais importante é a autoatribuição

${ }^{12}$ Cf. PONTIGNAT, Philippe; STREIFF-FENART, Jocelyne. Teorias da Etnicidade, pp. 65-84.

${ }^{13}$ Cf. F.BARTH. Grupos Étnicos e suas fronteiras. In: PONTIGNAT, Philippe; STREIFF-FENART, Jocelyne. Teorias da Etnicidade, pp.187-227. 
de uma unidade social diferenciada a partir de critérios de pertencimento ou diferenciação. A formação da identidade do grupo, nesse sentido, só ocorre em contato com padrôes mais gerais da sociedade, que, por sua vez, também se transformam. Desta forma, é enfatizado o caráter mais relacional e dinâmico da identidade étnica. A comunicação é enfatizada na construção social da identidade, porque por intermédio desse contato é que surgem padrões de comparação. Por isso, o grupo étnico é estabelecido dinamicamente, suscetível a redefiniçōes e transformaçōes, devido ao seu aspecto relacional. No caso dos grupos étnicos frutos da imigração, essa identidade étnica se transforma não só devido às mudanças da sociedade hospedeira, mas também às novas gerações de descendentes, que se distanciam da cultura de origem dos ascendentes. A cultura e os costumes dos ascendentes, por sua vez, também podem se transformar rapidamente no país de origem. Dada essa dinamicidade da etnicidade, talvez uma das afirmações mais relevantes dessa perspectiva seja que o grupo étnico pode permanecer com fronteiras, mesmo se muitos aspectos culturais e a língua original forem abandonados. Apesar de os grupos étnicos buscarem preservar suas culturas e tradições, nessa abordagem interacionista a definição do grupo étnico se concentra nas transformações das fronteiras, construídas entre os elementos do grupo e os que estão de fora. De uma forma geral, os elementos do grupo étnico praticam um "jogo com outras regras", com diferentes padrões éticos, comportamentais e de comunicação, que eles absorvem por meio da vivência de uma identidade étnica diferenciada. Esse "jogo interno" se transforma com as geraçōes e não apresenta uma barreira na incorporação de elementos que estão na sociedade majoritária. Nesse sentido, um fenômeno comum é o uso estratégico e pragmático de identidades múltiplas, principalmente no caso dos descendentes de imigrantes.

Do ponto de vista da ciência das religiôes, o ponto importante é a relação entre etnicidade e religião. Conforme Poutignat e Streiff-Fenart ressaltam, uma das formas de construção social da identidade étnica é por intermédio de um parentesco fictício, muitas vezes diretamente associado a mitos de origem comum (PONTIGNAT 1997:160-166). Dessa forma, a unidade do grupo é remetida a um tempo imemorial e revitalizada constantemente por meio de um calendário ritual e cerimônias de passagem, muitas vezes entendidas como uma obrigação social pelos adeptos, ocorrendo a preservação da identidade étnica pela socialização religiosa. De maneira semelhante, uma perspectiva analítica para a compreensão da religiosidade étnica é a teoria da identidade em Mol (1979). Considerando identidade como o esforço em preservar a existência, algo que ocorre tanto em indivíduos quanto em grupos e é uma característica importante dos pontos de vista biológico e social, a religião é estudada como sendo a sacralização da identidade. 
Nessa perspectiva, a evolução do grupo religioso é determinada pelas fronteiras do grupo étnico, que dependem da interação social e da absorção da religiosidade étnica pelas novas gerações. Para os que querem participar do grupo religioso, é frequentemente necessário um entendimento e até um comportamento semelhante ao do grupo étnico. Para a maioria dos adeptos que já pertencem ao grupo étnico, os elementos étnicos e religiosos são dificilmente diferenciáveis, o que limita a possibilidade de conversão e divulgação das ideias religiosas do grupo. Nesse sentido, uma religião étnica pode ser entendida como a sacralização de símbolos que impliquem uma identificação social diferenciada, sendo repassados mitos e ritos de uma identidade étnica para as próximas gerações, e preservados símbolos que lembram uma origem comum.

\section{Budistas Nikkeis no Brasil}

\section{História do Budismo Nikkeis no Brasil}

Uma das consequências importantes de se utilizar um conceito de grupo étnico centrado na interação social é destacar as estratégias de adaptação e sobrevivência de um grupo que teve sua origem na imigração, ressaltando o caráter dinâmico dessas transformações. Dessa forma, a comunidade de japoneses e de descendentes no Brasil pode ser estudada antropologicamente como um grupo étnico que foi desenvolvendo fronteiras, tanto com relação aos brasileiros quanto com relação aos japoneses, mas que diminui essas fronteiras de acordo com o contexto e a conveniência social. $\mathrm{O}$ uso de identidades múltiplas pode ser mais entendido como uma estratégia de adaptação e acomodação, fruto de uma identidade mestiça, do que como uma verdadeira ausência de fronteiras.

Com o passar do tempo, se por um lado a referência dos imigrantes era um Japão que não existia mais, também a história particular dos descendentes no Brasil estabeleceu uma identidade étnica a partir de uma visão construída do Japão e de uma assimilação seletiva da sociedade brasileira. Para uma diferenciação dos nikkeis em relação aos japoneses e brasileiros, descreverei os principais pontos históricos da interação social dos imigrantes, colocando esses pontos dentro do contexto da prática religiosa.

Do ponto de vista do estudo das religiōes, é necessário ressaltar que um Xintoísmo nacionalista originalmente trazido pelos imigrantes teve de ser traumaticamente abandonado na redefinição da identidade grupal após a Segunda Guerra Mundial. As alternativas foram a tendência de uma integração ao Brasil por intermédio do Catolicismo ou uma reafirmação de outra identidade japonesa, mais associada ao Budismo ou às novas religiōes. Para muitos nikkeis, essas opçôes se combinaram em algum tipo de convivência múltipla. No caso do Budismo, 
esse período posterior à Segunda Guerra significou uma nova fase, com o estabelecimento do vínculo institucional com o Japão mediante a fundação oficial de várias missões budistas, que reuniram templos e iniciativas já existentes e que estavam dispersas. Em muitos casos, as missões tiveram como objetivo também a pacificação das comunidades, já que muitas delas ainda estavam divididas devido à questão dos makegumi e kachigumi. ${ }^{14}$

Com isso, em 1952, foram fundadas as primeiras missões oficiais do $\mathrm{Bu}$ dismo no Brasil, com o estabelecimento oficial das escolas da Jôdo Shinshû, representadas pelos ramos Ôtani e Hompa. ${ }^{15} \mathrm{O}$ ramo Ôtani é mais conhecido pelo nome de Nambei Hoganji ou Higashi Hoganji. O ramo Hompa, que absorveu a maior parte dos pequenos templos existentes antes da institucionalização ${ }^{16}$, é também conhecido como Hompa Hoganji ou Nishi Hoganji. Em 1952, também foi fundado o templo Kannon da Tendaishû, em Diadema. Em 1953, foi iniciada a missão Jôdoshû e, em 1955, iniciou-se a missão Sôtô Zen e Nichirenshû. Em 1955, o Sumo Pontíficie da Honmon Butsuryûshû (HBS) fez uma visita assistencial ao Brasil, iniciando um contato mais oficial com a comunidade existente no país, em grande parte existente e se desenvolvendo a partir dos esforços do Rev. Nissui Ibaragui, então já considerado o fundador da HBS no Brasil, com centros em São Paulo e no Paraná. ${ }^{17}$

Em paralelo ao estabelecimento das missões, ocorreu um novo fluxo migratório do Japão para o Brasil de 1953 até 1962, com cerca de 50.000 imigrantes $^{18}$, o que trazia uma realimentação das tradições japonesas no Brasil e a chegada de novos movimentos religiosos, que tiveram um rápido crescimento no Japão do pós-guerra, após a proibição do Xintoísmo de Estado ${ }^{19}$. Em 1960, é fundado o

\footnotetext{
${ }^{14}$ Segundo entrevistas com líderes de templos, em alguns dos documentos oficiais de estabelecimento das missões, também se encontra essa proposta de pacificação, como por exemplo na ordem do Higashi Hoganji. Casos mais concretos podem ser obtidos a partir de histórias de fiéis, como pode ser lido por exemplo no jornal Brasil Jodo da Jôdoshû, na seção "Apresentando Fiéis da Comunidade" de abril de 2000, que mostra que, ainda em 1954, existiam conflitos sobre a vitória do Japão e que em alguns casos as missões religiosas contribuíram para a pacificação.

${ }^{15}$ Cf. R.GONÇALVES. A trajetória de um budista brasileiro”. In: USARSKI, Frank (org.): Budismo no Brasil2002, p. 183. Para efeitos de uma breve comparação desse momento histórico, se nos Estados Unidos a adaptação cultural se acelerou devido a uma história de imigração mais longa e como consequência das experiências dos campos de concentração, no caso do Brasil pode-se dizer que a missão foi iniciada no pós-guerra.

16 Cf.R.GONÇALVES. O Budismo Japonês no Brasil. In: Sinais dos Tempos, pp. 167-180.

${ }^{17}$ Cf. H.NAKAMAKI. A Honmon - busuryû-shû no Brasil. In: USARSKI, Frank (org.), O budismo no Brasil, pp. 96-99..

${ }^{18}$ SAITO, 1980, pp. 83-84.

${ }^{19}$ Ao contrário do fluxo imigratório anterior, existia nesses novos imigrantes a opção pela permanência definitiva, muitos deles vindos de antigas possessões e colônias japonesas. Também em contraste com os outros imigrantes, muitos deles tiveram a Amazônia e a Região Nordeste do Brasil como destino.
} 
Distrito Brasil da Sôka Gakkai e, nos anos seguintes, são criadas várias sedes regionais. ${ }^{20}$ Já as atividades da Risshô Kôseikai no Brasil foram iniciadas em 1971. Entre 1971 e 1976, foi construído o templo Joganji Fudô Myô-ô da Tendaishû. A Reyukai foi registrada no Brasil em 1975, a partir de um núcleo que tinha sido formado após a vinda do imigrante Toku Suzuki ao Brasil, em 1969. ${ }^{21}$

O estabelecimento e a institucionalização desses movimentos foram o resultado de uma necessidade religiosa dos nikkeis. As atividades econômicas da família, principalmente no ambiente rural, eram baseadas no conceito de $i e$, que estipula que o patrimônio conjunto da família é administrado pelo filho primogênito. Em termos de classe social, essas atividades se enquadram no que Maeyama chamou de "velha classe média", identificada a partir da continuidade das atividades dos pioneiros imigrantes, principalmente na agricultura e nos pequenos negócios familiares, que geralmente não dependiam de uma formação educacional e uma consequente maior integração e participação na vida nacional. Apesar do abandono do Xintoísmo nacionalista, a religião ainda continuou tendo um caráter étnico para a maioria dos japoneses e seus descendentes, o que se manifestou no estabelecimento do Budismo.

Os imigrantes que retomaram o Budismo decidiram recuperar o sistema de $i e$, iniciando uma extensão das famílias japonesas no Brasil, das quais eles seriam os ancestrais vivos. Essas características da vida religiosa dos japoneses no Brasil do pós-guerra foram descritas por Takeshi Maeyama, que ainda defendeu uma correlação entre religião, parentesco e classe social. Ele observou, na época, que existia uma clara dicotomia entre o que a comunidade nipo-brasileira chamava de "religião japonesa" e "religião brasileira". Como "religião japonesa", entendia-se não só o Xintoísmo e o Budismo como também as novas religiōes japonesas, que, então, utilizavam somente o japonês e eram frequentadas apenas por japoneses e seus descendentes. Em contraposição aos filhos mais velhos e tradicionais, os mais novos foram muitas vezes incentivados a se identificarem mais definitivamente com a sociedade brasileira, muitas vezes emigrando para as áreas urbanas em busca de uma melhor educação.

Um dos principais polos de atração foi dado pelo crescimento da cidade de São Paulo, que também oferecia boas oportunidades de educação. Semelhante a muitos descendentes de imigrantes, uma mudança geográfica muitas vezes

\footnotetext{
${ }^{20}$ Cf. R.A.PEREIRA. O Budismo Leigo da Associação Brasil Sôka Gakkai Internacional: In: Frank Usarski (org.) O Budismo no Brasil, pp.265-266.

${ }^{21}$ Cf. K.MORI, Koichi. Vida Religiosa dos Japoneses e seus Descendentes Residentes no Brasil e Religiões de Origem Japonesa”. In: Comissão De Elaboração Da História dos 80 Anos da Imigração Japonesa no Brasil (org.). Uma Epopéia Moderna: pp.559-603.
} 
enfraquece os laços com a comunidade étnica, que se combinava com a família, estimulando uma integração mais estrutural, quer seja com casamentos interétnicos ou por meio da participação em sociedades sem vínculo étnico. Ao invés de receber as propriedades da família como herança, como no caso dos filhos mais velhos, os mais novos recebiam a oportunidade e o apoio para estudar na universidade. Em geral, esses irmãos mais novos tiveram mais liberdade de se converter ao Catolicismo, que se caracterizou como um importante elemento da identidade nacional no Brasil, em substituição ao Xintoísmo nacionalista. ${ }^{22}$

De uma forma geral, pode-se dizer que esse trânsito estratégico entre as culturas brasileira e japonesa foi bem-sucedido, buscando maximizar o ganho social por intermédio de uma adaptação cultural no que pareceu necessário e conveniente. Um ponto de diferenciação em relação à sociedade brasileira em geral é a relativa ascenção social da comunidade nikkeis. A partir dos anos 70, com o chamado milagre econômico brasileiro e com a progressiva integração dos nikkeis no sistema educacional, vem se consolidando a importância econômica da comunidade. ${ }^{23}$ Em paralelo, a ascensão do Japão no cenário mundial e o crescente interesse pela cultura japonesa no mundo ocidental fizeram com que os imigrantes e os descendentes de japoneses no Brasil tivessem uma imagem diferenciada para os brasileiros, ainda que muitas vezes por meio de estereótipos ou preconceitos. ${ }^{24}$

De qualquer forma, é fato a integração estrutural dos nikkeis. Se, nos anos 60 e 70, existia a busca por uma integração nos diversos setores da sociedade brasileira, hoje há dados que mostram uma assimilação estrutural em uma taxa bastante alta. De fato, alguns dados estatísticos comprovam essa tendência: os

${ }^{22}$ Cf. R.SHOJI, The Failed Prophecy of Shinto Nationalism and the Rise of Japanese Brazilian Catholicism, In: Japanese Journal of Religious Studies, pp.13-38.

${ }^{23}$ Diversas estatísticas refletem essa particularidade. Segundo o IBGE, os brasileiros de origem asiática (majoritariamente descendentes de japoneses) se encontram no topo da pirâmide social. Em termos comparativos, a renda dos japoneses e seus descendentes é cerca de $76 \%$ maior que os brasileiros de origem europeia e 4,3 vezes maior que os brasileiros de origem africana, cf. Relatório PINAD do IBGE realizado em 1988. Dados semelhantes podem ser encontrados na produção nacional agrícola: a comunidade japonesa é responsável por $70 \%$ da produção brasileira de batatas, $45 \%$ da produção de soja, $10 \%$ da produção de café, $94 \%$ da produção de chá e $50 \%$ da produção de ovos. Isso ocorre apesar de somente $10 \%$ dos nikkeis, ou seja, menos de $0,1 \%$ da população brasileira, trabalharem na agricultura. Outros dados mostram que o nível educacional dos japoneses e seus descendentes é também bastante maior que a média nacional.

${ }^{24}$ Para uma pesquisa qualitativa, na área da psicologia social, sobre os estereótipos associados mutuamente aos brasileiros e à comunidade nikkeis, consultar Saito, T. 1986. Uma análise desses clichês é interessante porque eles mostram as fronteiras e uma imposição de diferenças reais ou imaginadas. Com relação aos participantes do grupo minoritário, esses elementos também mostram pontos de conflito e permanente justificação com a sociedade majoritária, o que não deixa de se apresentar como uma motivação de identificação que define comunidades e relacionamentos sociais. 
casamentos interétnicos já representam cerca de $46 \%$ do total. ${ }^{25}$ Cerca de $28 \%$ dos nikkeis são mestiços, um número que aumenta progressivamente com as gerações: $6 \%$ são mestiços na segunda geração, $42 \%$ na terceira e $62 \%$ na quarta (MIYAO 1996:78). No que se refere diretamente ao comportamento religioso, quase $60 \%$ já se declaram católicos e somente cerca de $25 \%$ ainda se dizem pertencentes a uma religião japonesa (MORI 1992:594). ${ }^{26}$

Além dessa rápida integração e da morte dos imigrantes japoneses, que estão mais associados aos templos devido ao vínculo étnico, muitas religiōes japonesas, rincipalmente templos budistas, têm perdido membros devido ao fenômeno decasségui. A partir dos anos 80 , especialmente devido à crise econômica brasileira e com a necessidade de mão-de-obra no Japão, muitos nikkeis se deslocaram para o Japão como trabalhadores temporários e atualmente existem cerca de 300.000 brasileiros no Japão. Chamados de decasséguis (literalmente, "sair para ganhar dinheiro", um termo também usado para os imigrantes japoneses no Brasil), muitos deles executam serviços braçais que os japoneses não estavam mais dispostos a realizar. Com o passar do tempo, uma parcela dos decasséguis tem optado por se estabelecer definitivamente no Japão, sendo que outros retornam ao Brasil com o dinheiro que conseguiram economizar. Apesar de teoricamente ser uma possibilidade de contato com a cultura japonesa para os nikkeis que trabalham como decasséguiis ${ }^{27}$, por outro lado esse fenômeno também é responsável por uma sensível diminuição do número de membros das chamadas religiōes japonesas. Esses fatores têm aumentado a preocupação de adaptação dos templos tradicionais, que, devido a perda de adeptos, têm começado a tratar o problema como uma questão de sobrevivência.

No que diz respeito à identidade étnica atual, embora seja um consenso a progressiva integração estrutural da comunidade dos japoneses e seus descendentes, é preciso notar uma diferenciação étnica que ainda persiste, mas que encontra um difícil espaço de expressão em uma sociedade como a brasileira, que é multicultural, mas que dificilmente reconhece um pertencimento observar essa diferenciação étnica é a autodenominação dos nikkeis como um grupo étnico que tem limites para com os japoneses e brasileiros. No caso dos decasséguis, por exemplo, é muitas vezes citado um conflito de identidade, já que o imigrante nikkeis se sente

\footnotetext{
${ }^{25}$ Cf. J.LESSER. A negociação da identidade nacional: Imigrantes, minorias e a luta pela etnicidade no Brasil, p. 296.

${ }^{26}$ Dados estatísticos de pertença múltipla ainda são quase desconhecidos e em geral pouco pesquisados no Brasil. Conforme será argumentado adiante, em pesquisas qualitativas, observa-se uma combinação religiosa no caso de muitos nikkeis.

${ }^{27}$ Cf. S.MIYAO. Os dekassegui como novos transmissores da cultura japonesa". In: NINOMIYA, Masato (org.). O futuro da comunidade nikkei. pp.77-84.
} 
um brasileiro no Japão, mas é chamado de japonês no Brasil, criando padrões mesclados de comportamento. Em um contexto mais geral, um dos aspectos que contribuem decisivamente para umaidentidade étnica na comunidade nikkeis são os traços físicos e fisionômicos diferenciados. Se, com os descendentes de outros imigrantes, essa diferenciação se perde na variedade dos tipos físicos que compõem os brasileiros, no caso dos nikkeis ela se encontra presente até em descendentes que não tiveram quase nenhum contato com os costumes japoneses. Mesmo com relação às novas gerações de descendentes, também tem sido indicada uma permanência da consciência étnica pelos aspectos como alimentação e tendência na formação de amizades, ainda que a língua e o interesse pela música japonesa venham se transformando rapidamente. Outro aspecto de diferenciação étnica é que ainda existem muitas atividades e festivais da cultura japonesa organizados pelos nikkeis, buscando se firmar em contraste a uma assimilação total e tentando destacar o perigo de perder potenciais contribuiçôes que a cultura japonesa poderia trazer para o Brasil. Adicionalmente, existem publicações que simplesmente veiculam uma identidade nikkeis, algumas delas tendo um considerável sucesso entre jovens e interessados na cultura japonesa. ${ }^{28}$

A identidade dos nikkeis, entendidos como um grupo étnico a partir de sua interação com japoneses e brasileiros, se reflete diretamente no que diz respeito às práticas dos que ainda são budistas, mas ainda reflete pouco os interesses das novas gerações. A seguir, descreverei os padrōes gerais que estimulam uma identidade étnica e aqueles que mostram uma apropriação da religiosidade brasileira, pontos gerais de separação e de contato que podem ser reconhecidos nos templos e devotos budistas.

\section{Reinterpretação do Budismo Japonês: Combinações na Religiosidade Nikkeis}

Conforme ressaltado, em uma análise de um processo histórico mais longo, é interessante observar que o Xintoísmo de Estado, que refletia a identidade étnica antes da Segunda Guerra, foi progressivamente sendo substituído pelo Catolicismo, que nessa época era considerado a religião que representava o Brasil. Em termos atuais, no caso dos nikkeis, a múltipla filiação religiosa tem muitas vezes um papel integrador, no sentido de incorporar elementos da sociedade majoritária. No caso dos devotos, é comum a sobreposição de rituais budistas e de outras religiōes, já que a participação em rituais budistas é muitas vezes entendida como um ritual da

\footnotetext{
${ }^{28}$ Como exemplos dessas publicações podem ser citados o São Paulo Shimbun, o Jornal do Nikkeis, IPC International (para decasséguis) e a revista Made in Japan, entre outros.
} 
família, uma obrigação para impedir infortúnios ou uma manifestação de respeito. Dessa forma, uma continuidade das religiōes étnicas também se dá na convivência simultânea com as religiōes majoritárias na sociedade brasileira, algo que é difícil de avaliar e quantificar empiricamente. $\mathrm{O}$ fato de a religiosidade japonesa, excetuando os novos movimentos religiosos, ser familiar e orientada a rituais e não a partir de crenças pessoais, possibilita um espaço de convivência múltipla no caso dos nikkeis, no qual diferentes religiōes assumem diferentes papéis que podem ser entendidos entre o polo de integração e etnicidade. Uma múltipla convivência religiosa é relatada em quase todos os templos étnicos no Brasil, ainda que uma exceção tenha que ser feita a alguns grupos derivados do Budismo de Nichiren. Por isso, uma perspectiva teórica que analise somente a partir das instituiçóes pode ser bastante inadequada quando se observam diretamente os adeptos, principalmente quando eles vivem em um ambiente de recepção que, ao contrário dos EUA e dos países europeus, apresenta uma tendência de convivência religiosa múltipla como o Brasil. Uma perspectiva não centrada nas instituições revela que existem combinações religiosas que expressam uma realidade ainda mais diferenciada, que podem ser entendidas a partir de diferentes níveis de identidade e de uma religiosidade popular nipo-brasileira.

Nesse sentido, Hans Mol propôs que existem diferentes identidades nos níveis pessoal, grupal e social. ${ }^{29}$ Essas identidades podem convergir ou divergir, o que pode ser refletido nas práticas religiosas. No Japão, por exemplo, ele cita uma correlação entre identidade comunitária e Xintoísmo, a identidade familiar e Budismo, e identidade pessoal e Cristianismo. A presença de vários níveis de identidade pode ser ainda mais clara em sociedades na qual uma convivência religiosa múltipla é algo comum, já que nesses casos uma questão importante é o papel que diferentes religiôes têm na vida de um mesmo indivíduo ou grupo. No caso dos imigrantes e descendentes em geral, é possível que diferentes práticas tenham significados para diferentes níveis de pertencimento social, principalmente para as novas geraçôes, em um padrão que depende da sociedade receptora.

No caso do Brasil, o pertencimento a instituições que simbolizem uma integração à sociedade majoritária não impede a participação em uma religiosidade que implique uma identidade étnica e familiar. Um espaço étnico, o que pode ser a justificação social de um templo budista, modelado originalmente como um pequeno Japão, não é necessariamente a totalidade da vida religiosa dos adeptos. Isso se verifica com a convivência múltipla em diversas religióes, um elemento que caracteriza o comportamento de brasileiros e japoneses. No monoteísmo

${ }^{29}$ Cf. H.MOL. Identity and Religion: International, Cross-Cultural Approaches, pp. 10-14. 
tradicional, um relativismo religioso pode ser descrito como uma espécie de heresia, no qual rituais de diferentes religiōes são contextualizados e destinados para esferas e fins diferentes. No entanto, ainda que existam muitas diferenças na maneira de realizar essa convivência múltipla, uma sensação de incompatibilidade não é a experiência de grande parte dos brasileiros e japoneses. Transpondo essa tendência para os nikkeis, se os brasileiros podem ser, por exemplo, católicos e umbandistas, e os japoneses xintoístas e budistas, os nikkeis podem ser, por exemplo, católicos e budistas, ou mesmo espíritas e xintoístas. Por essa razão, mesmo atualmente, não é raro encontrar o butsudan, o altar budista para os antepassados, em famílias que se "converteram" ao Catolicismo.

Também não é incomum que figuras católicas sejam colocadas nesses altares domésticos. Se tipicamente muitos japoneses nascem xintoístas e morrem budistas, uma parte dos nikkeis nasce católica, mas é sepultada com rituais budistas, por exemplo, em uma expressão de pertencimento religioso múltiplo, fruto de uma identidade nikkeis que sofre influências brasileiras e japonesas. Em um outro nível de combinação, que pode ser chamado de sincretismo em um sentido mais amplo, ocorre a incorporação de elementos de outras religiōes, estando também presente no uso de um vocabulário religioso mais livre e informal, em geral a partir do Catolicismo. O Dia de Finados no Brasil, que ocorre no dia 2 de novembro, já foi tradicionalmente interpretado como um Obon brasileiro.

Por outro lado, se nos EUA, por exemplo, é comum nos templos japoneses a presença de escolas dominicais, entre outras claras influências do Protestantismo ${ }^{30}$, a Honmon Butsuryûshû do Brasil, por exemplo, tem utilizado o termo "catequese", no que se refere aos seus encontros de instrução doutrinária. Nas escolas do Terra Pura, em outro exemplo, é possível observar ocasionalmente um gesto católico como o sinal da cruz, comum entre os adeptos que só frequentam o templo nas chamadas missas de família, dedicadas aos antepassados. A maioria dos templos budistas também acaba incorporando cerimônias como batismo e casamento em um ritual mais ocidentalizado, ainda que se busque imbuir essas cerimônias de significados budistas. O batismo é um termo usado, por exemplo, para designar a iniciação ao Budismo ou como uma apresentação da criança ao templo.

\section{Perspectivas para o Futuro: Fronteiras Étnicas e de Geração}

A partir de meados da década de 70 , se as chamadas novas religióes japonesas buscaram se adaptar e atrair brasileiros, ainda que atualmente o controle

\footnotetext{
${ }^{30}$ Cf. D.YOO. A Religious History of Japanese Americans in California. In: MIN, Pyong Gap; KIM, Jung Ha (eds.). Religions in Asian America: pp.121-142; R.SEAGER. Buddhism in America. pp.53-59.
} 
ainda permaneça predominantemente com descendentes de japoneses, no caso de muitos templos um esforço de abertura étnica raramente existiu, com exceção de algumas correntes nos templos étnicos Zen, que atraem interessados em meditação e simpatizantes no templo da Koyasan Shingon, em Suzano. Essas escolas mais tradicionais se encontram reunidas na Federação de Seitas Budistas do Brasil, que, desde 1958, reúne as escolas Zen, Jôdoshû, Jôdo Shinshû (ramos Higashi e Nishi) e Nichirenshû. Características de um Budismo étnico também podem ser encontradas em grupos como a Igreja Budista Nambei Yugazam Jyomiyoji, de orientação Shingon, ou mesmo em algumas novas religiōes que não têm tido uma participação majoritária de brasileiros, como os grupos Shinrankai, Honmon Butsuryûshû e a Risshô Kôseikai. A seguir, serão descritas as características deste Budismo étnico a partir de pesquisas de campo com as instituiçóes citadas, o que incluiu entrevistas, observações de rituais e análise de programação e das publicações dos grupos na mídia.

Com o surgimento das novas gerações, o que é chamado de Budismo japonês se transformou em um Budismo Nikkeis, com a combinação de padrões brasileiros e japoneses, mas sem uma abertura étnica significativa. O Budismo Nikkeis se baseia, e em muitos grupos essa característica ainda é uma realidade, na identidade étnica e na religiosidade familiar dos descendentes, que se interessam pelo Budismo principalmente devido aos festivais e cerimônias fúnebres, considerando o templo budista mais como um centro de cultura japonesa. Confirmando o ciclo proposto por Mullins (1987), com a morte dos imigrantes e a progressiva integração estrutural e cultural dos descendentes, muitos templos têm enfrentado uma significativa redução no número de adeptos e monges, tendo que encontrar novas maneiras de sustentar a motivação de sua existência social. No entanto, um esforço de adaptação cultural e linguística não tem sido acompanhado de uma abertura étnica, sendo mais motivado pela tentativa de acompanhar as fronteiras que definem o grupo.

De uma forma geral, o esforço de adaptação e tradução do Budismo Nikkeis tem sido feito visando muito mais aos descendentes de japoneses do que aos brasileiros, em um movimento de resistência a uma tendência de integração total ao Brasil. O papel desses templos reflete uma tendência de valorização da etnicidade, na sutil e paradoxal dificuldade de inclusão dos descendentes de japoneses na identidade nacional brasileira. Apesar da adaptação linguística e cultural dos templos, esses fatores de resistência geraram uma tendência pequena de adaptação da doutrina para o ambiente brasileiro que buscasse desvincular o Budismo do grupo nikkeis. Em alguns casos, a adaptação foi feita com atividades que, se não são budistas, se associam estreitamente à cultura japonesa. Praticamente, todos os templos oferecem atividades que não se vinculam diretamente à religião, como 
cursos de japonês, karaokê, ikebana, danças típicas, ou mesmo artes marciais como karatê e kendô. Esse aspecto faz até com que alguns templos acabem tendo o aspecto religioso e doutrinal como relativamente secundário, já que a justificação para sua existência social e sua fonte de renda se dá mais a partir da sua oferta como um centro cultural japonês. Ainda que essa oferta possa atrair simpatizantes da cultura japonesa para o Budismo, esse Budismo diluído também é um veículo de propagação e valorização da influência japonesa na identidade nikkeis e para eventuais convertidos.

Em alguns casos, existem pequenos grupos de brasileiros, a maioria somente simpatizantes, que buscam o Budismo dentro dos templos étnicos. Dificilmente essas congregações são paralelas no sentido de uma ausência de interação, conforme observado nos templos Theravada dos EUA por Numrich, apesar de existirem atividades mais direcionadas a um ou outro grupo. No aspecto mais diretamente associado à religião, a maior participação de brasileiros se dá a partir de horários de meditação ou de dias de retiro (no caso do Zen) ou a partir do oferecimento de consultas e cerimônias para a resolução de problemas (no caso do Budismo esotérico), o que varia segundo a disponibilidade de monges e a abertura da comunidade. Algumas dessas atividades são pagas e isso garante seu prosseguimento, atraindo interessados na cultura japonesa ou em uma religiosidade alternativa que são motivados por um interesse intelectual ou na busca de um status esotérico.

No caso do Budismo da Terra Pura é mais difícil encontrar ressonância nas expectativas que os brasileiros esperam encontrar ${ }^{31}$, ainda que práticas amidistas tenham atraído intelectuais que foram bastante importantes para a divulgação do Budismo em geral. Em alguns casos, uma das estratégias tem sido oferecer uma meditação baseada em alguns sutras de contemplação da Terra Pura, mas essa atividade, heterodoxa no contexto japonês, ainda encontra interrupções e resistências nas comunidades. Outra alternativa encontrada para criar pequenos espaços nos quais os brasileiros possam se interessar pela doutrina da Terra Pura foi o oferecimento de cursos doutrinais pagos, nesse caso no ramo Higashi da Jôdo Shinshû, uma alternativa que se tem estabelecido de uma forma mais contínua e com um apoio mais institucional. Como tendência geral, no entanto, as escolas da Terra Pura ainda têm pouquíssimos brasileiros e estão bastante concentradas nos nikkeis, apresentando correntes de clara resistência a uma maior abertura. Como as escolas da Terra Pura apresentam a maior estrutura de templos e o maior número

\footnotetext{
${ }^{31}$ Cf. R.SHOJI, Uma Perspectiva Analítica para os Convertidos ao Budismo Japonês no Brasil, In: REVER, pp. 85-111;; F.USARSKI. O Budismo no Brasil - um resumo sistemático. In: USARSKI, Frank (org.). $O$ Budismo no Brasil, pp. 9-33; P.CLARKE. Japanese New Religious Movements in Brazil: From ethnic to 'universal' Religions. In: CRESSWELL, Jamie; WILSON, Bryan (eds.). New Religious Movements, pp.197-211.
} 
de adeptos no contexto do Budismo tradicional, tendo perdido um grande número de adeptos nos últimos anos, tem sido especialmente ressaltada a necessidade de uma reorientação linguística e cultural nesses templos. Como norma geral de todos os templos étnicos, no entanto, isso tem sido feito priorizando os descendentes e buscando preservar a herança japonesa.

Para poder destacar os motivos dessa estratégia de sobrevivência é relevante uma abordagem interacionista, já que as fronteiras do grupo étnico são definidas pela evolução e pela diferenciação do grupo em relação à sociedade majoritária. Nesse caso, um dos fatores básicos para a adaptação de uma religião de imigrantes em outro contexto cultural, independentemente da intenção missionária, é a atitude valorativa existente. Uma assimetria nas relaçôes entre os dois grupos, seja devido a uma diferença histórica ou socioeconômica, seja devido a uma suposta superioridade cultural, altera significantemente o esforço de adaptação do grupo imigrante. Por isso, o encontro entre religiôes e o esforço de adaptação de uma religião são dificilmente generalizáveis, variando conforme a situação histórica e o modo como diferentes grupos de imigrantes e nativos se analisam, verificando dessa forma o que pode ser adaptado e de que maneira.

As diferenças existentes e supostas entre os nikkeis e brasileiros, causadas por fatores culturais, históricos e socioeconômicos, têm por isso um papel não só na formação da identidade nikkeis, mas também na adaptação do Budismo no Brasil. Um aspecto geral é o fato de o Brasil ainda ter uma carência em infraestrutura básica e um alto nível de desigualdade social. Um Budismo no contexto dos países em desenvolvimento, ainda que tenha sido sugerido em alguns trabalhos acadêmicos $^{32}$, ainda não foi suficientemente descrito e estudado, sendo o Brasil um importante exemplo de como essas características podem atuar.

No caso do Budismo étnico, isso tem como consequência não só diferenças nos recursos materiais disponíveis nos templos, mas também pode influir na sustentabilidade econômica das atividades, na distribuição de poder e no foco das atividades sociais. Nesse contexto, a assistência social é um campo de atuação que pode ser importante, já que existem áreas de demanda social no Brasil.

No caso do Budismo Nikkeis, os principais beneficiados dessas atividades sociais costumam pertencer à própria comunidade étnica. Um exemplo de importante atuação social é o trabalho da escola Jôdoshû, que associou seu trabalho missionário budista à assistência social ${ }^{33}$, a partir de duas instituições que foram

\footnotetext{
${ }^{32}$ Para uma coletânea de artigos sobre o Budismo na África, ver M.CLASQUIN; J.S. KRÜGER. Buddhism and Africa..

${ }^{33} \mathrm{~A}$ ordem teve como pioneiro no Brasil o monge Ryoshin Hasegawa, fundador e professor associado à assistência social. Ele defendia que a missão deveria estar concentrada no tripé educação, Budismo e assistência social.
} 
$82 \mid$ Rafael Shoji

iniciadas a partir do templo, a Kodomo no sono, em São Paulo, inicialmente destinada a crianças excepcionais, e a Wajunkai, em Maringá, destinada a idosos. Essas entidades têm uma diretoria e atividades independentes e, apesar de seguirem orientação budista, aceitam a participação de quaisquer grupos ou pessoas. A Kodomo no sono foi a princípio criada para atender crianças nikkeis, mas atualmente está também aberta aos brasileiros.

A associação de idosos foi inicialmente instituída para atender aos imigrantes que não tinham família e sofreu uma ampliação nos últimos anos, depois da doação de um terreno pela Prefeitura de Maringá. Em relação a um confronto mais direto, a maior parte dos líderes entrevistados afirmou que ainda existem nikkeis que têm resistências contra atividades mais direcionadas para os brasileiros, ou pelo menos correntes que são claramente contra uma abertura étnica. Outro aspecto dessa interação, estreitamente relacionado à representação étnica, se refere ao sustento econômico dos templos. Um ponto ressaltado por quase todos os representantes do Budismo étnico é que os brasileiros não têm o costume de associar sua opção espiritual a uma contribuição voluntária. Por isso, frequentemente os nikkeis também são os únicos provedores econômicos dos templos, com o auxílio das missões japonesas. Isso reforça ainda mais a tendência de que esses templos representam aqueles que menos se sentem inclinados a uma integração total à sociedade brasileira, preservando um centro cultural e uma identidade étnica por meio de uma religiosidade baseada na família e no culto aos antepassados, o que por sua vez tem muito pouco interesse para os brasileiros. Talvez devido a esses fatores, o elemento étnico ainda é determinante nas relaçóes de poder

e na administração dos templos. Isso não impede que existam muitos conflitos na disputa de poder nos templos, mas em geral essas disputas seguem uma lógica interna ao grupo nikkeis. Na prática, devido ao fato dos nikkeis deterem o controle político, a preservação da memória e cultura nikkeis são aspectos mais enfatizados, em detrimento de uma maior inserção dentro da cultura brasileira.

Por esse motivo, apesar do relativo interesse de muitos brasileiros pelo Budismo, a estratégia de sobrevivência do Budismo étnico consiste mais concretamente na atração dos descendentes das famílias nikkeis que já participam dos templos. Com isso, o papel dos templos contribui na preservação da influência japonesa na identidade étnica dos nikkeis, que pode sobreviver em pelo menos uma parcela dos descendentes. Algo que pode ser encontrado em muitos templos étnicos são as congregaçôes de descendentes, determinadas pelas diferentes geraçôes e pela progressiva adaptação ao Brasil. Essas diferentes congregações de descendentes mantêm contato entre si, não sendo paralelas no sentido de Numrich, mas mantendo atividades independentes. Elas podem ser observadas não só através de entrevistas, mas também na análise da programação e nos grupos de atividades existentes nos 
templos. Se a língua preferencialmente utilizada para a comunicação com a geração dos pioneiros e de muitos nisseis é o japonês, a maioria dos descendentes das mais novas gerações só entendem o português. Em alguns jornais de templos, existem as duas línguas, com notícias diferentes para os diferentes tipos de audiência. Se, para os mais velhos as artes tradicionais japonesas são enfatizadas e a história dos imigrantes e dos templos é um elemento importante ${ }^{34}$, no caso dos jovens as atividades conjuntas se destinam mais a reuniōes de grupo e manutenção de um espaço de convivência nikkeis por meio do escotismo, das práticas esportivas ou das reuniōes de confraternização e karaokê para jovens.

Em ambas as congregações de descendentes, os aspectos espirituais do Budismo são um elemento relativamente secundário e, para os mais jovens, o Budismo é frequentemente retratado como uma religião somente para os mais velhos. Ainda que alguns dos descendentes possam até desenvolver ou ser atraídos para uma parcela mais contemplativa, principalmente aqueles que desenvolveram um interesse mais intelectualizado, a maior parte dos devotos se refere à prática religiosa como uma obrigação ou tradição familiar, muitas vezes como forma de se livrar de infortúnios que a falta do culto aos antepassados poderia trazer. Mesmo atualmente, o Budismo Nikkeisé praticado como a sacralização de uma identidade étnica, mediante os rituais de veneração aos ancestrais e da celebração do esforço dos imigrantes pioneiros, fornecendo para os de fora um espaço de preservação e divulgação da cultura japonesa.

Enquanto uma identidade étnica dos nikkeis sobreviver, mesmo que se transforme, sempre haverá uma possibilidade de sobrevivência e de adaptação do Budismo étnico, ainda que as tendências são de que ele diminua sua estrutura e o número de adeptos com o passar das geraçôes. ${ }^{35}$

\section{Conclusões}

A partir de um conceito de etnicidade baseado na interação social, é possível analisar diferentes tendências na adaptação das religiōes japonesas no Brasil. Do ponto de vista das instituições, em uma afirmação teórica mais geral, as religiôes trazidas pelos imigrantes oscilam entre duas estratégias, no que se refere à sua

\footnotetext{
${ }^{34}$ Um dos principais eventos da Federação de Seitas Budistas, por exemplo, é o culto em memória aos imigrantes pioneiros, celebrado em junho.

${ }^{35}$ Esse é o caso da BCA nos EUA, que já inclui 100 anos de adaptação, mas ainda se constitui majoritariamente de adeptos nikkeis, devido a diversas razões, cf. K.TANAKA. Issues of Ethnicity in the Buddhist Churches of America. In: WILLIAMS, Duncan Ryûken; QUEEN, Christopher S. (eds.). American Buddhism, pp.3-19 e A.BLOOM. Shin Buddhism in America. In: PREBISH, Charles S.; TANAKA, Kenneth K. (eds.). The Faces of Buddhist America, pp.31-48.
} 
permanência social. Uma delas maximiza a abertura cultural, no sentido de ampliar o número de adeptos nativos, mas buscando eventualmente manter uma base étnica constante que garanta sua sustentação. Os imigrantes e os descendentes que se identificam com esse projeto apresentam em geral propósitos mais universalistas e favoráveis à integração, sendo estimulados pela sua própria religião nesse processo. Essa característica é frequentemente encontrada na evolução das Novas Religiōes Japonesas no Brasil, que se adaptam rapidamente e também estimulam uma clara abertura étnica. No polo oposto, no qual a identidade imigrante é a prioridade, essa abertura cultural é constantemente minimizada, acompanhando somente a evolução das fronteiras do próprio grupo étnico, que só tem uma alteração identitária mais radical com o passar das gerações. A esse último caso pertence ao Budismo Nikkeis associado a escolas budistas tradicionais, sendo mais conservador na sua adaptação e enfrentando um grande desafio com a mudança da língua e das fronteiras do grupo. Nesse caso, é relevante analisar os critérios que definem as fronteiras do grupo e as práticas religiosas que podem veicular tal identidade étnica.

Instituições com congregações independentes, tradicionalmente com diferentes estratégias para diferentes públicos, não são tão comuns nos templos nikkeis no Brasil. Quando existem, dificilmente as congregações são paralelas no sentido de não apresentarem nenhuma interação, podendo existir conflitos se algum dos grupos não quiser conviver com essa ambiguidade ou se sentir o único provedor econômico da instituição, algo que ocorre rapidamente no Brasil. Nos templos étnicos do país, diferentes grupos são comuns como uma expressão da presença de diferentes geraçóes de adeptos, o que gera outras estratégias de sobrevivência social, que se esforça por adaptações culturais e linguísticas, mas busca manter os limites étnicos do grupo. Com a possibilidade de uma religiosidade múltipla no Brasil e dada a particular história dos nikkeis, também pode ser constatado que o Budismo representa uma religião familiar e de simbolização da identidade étnica, enquanto religiões brasileiras, principalmente o Catolicismo, são praticadas como uma forma de pertencimento à sociedade majoritária.

Essa possibilidade de ambiguidade religiosa em ambiente de recepção para o Budismo, em contraposição aos EUA e Europa, permite um relaxamento das tensões étnicas, mas também uma diluição e ambiguidade na sua continuidade e estratégia de adaptação.

\section{Referências Bibliográficas}

Apresentando Fiéis da Comunidade. In: Jornal Brasil Jodo, n. 5, Ano II, (2000): s/p.

ASAI, Senryô; WILLIAMS, Duncan Ryûken. Japanese American Zen Temples: Cultural Identity and

Economics. In: WILLIAMS, Duncan Ryûken; QUEEN, Christopher S. (eds.). American Buddhism:

Methods and Findings in Recent Scholarship. Richmond: Curzon Press, 1999, pp.20-35. 
BARTH, Fredrik. Grupos Étnicos e suas fronteiras. In: PONTIGNAT, Philippe; STREIFF-FENART, Jocelyne. Teorias da Etnicidade. Seguido de Grupos Etnicos e suas Fronteiras de Fredrik Barth. São Paulo: Editora da Unesp, 1997, pp.187-227.

BLOOM, Alfred. Shin Buddhism in America: A Social Perspective. In: PREBISH, Charles S.; TANAKA, Kenneth K. (eds.). The Faces of Buddhist America. Berkeley: University of California Press, 1998, pp.31-48.

CHANDLER, Stuart. Chinese Buddhism in America: Identity and Practice. In: PREBISH, Charles S.; TANAKA, Kenneth K. (eds.). The Faces of Buddhist America. Berkeley: University of California Press, 1998, pp.13-30.

CHANDLER, Stuart. Placing Palms Together: Religious and Cultural Dimensions of the Hsi Lai Temple Political Donations. In: WILLIAMS, Duncan Ryûken; QUEEN, Christopher S. (eds.). American Buddhism: Methods and Findings in Recent Scholarship. Richmond: Curzon Press, 1999, pp.36-56.

CLARKE, Peter. Japanese New Religious Movements in Brazil: From ethnic to 'universal' Religions. In: CRESSWELL, Jamie; WILSON, Bryan (eds.). New Religious Movements: Challenge and Response. London: Routledge, 1999, pp.197-211.

CLASQUIN, M.; KRÜGER, J. S. Buddhism and Africa. Pretoria: University of South Africa, 1999.

EARHART, H. Byron (ed.). Religion in the Japanese Experience: Sources and Interpretations. Belmont: Wadsworth Publishing Company, 1997.

FIELDS, Rick. Divided Dharma: White Buddhists, Ethnic Buddhists, and Racism. In: PREBISH, Charles S.; TANAKA, Kenneth K. (eds.). The Faces of Buddhist America. Berkeley: University of California Press, 1998, pp.196-206.

GONÇALVES, Ricardo Mário. O Budismo Japonês no Brasil: Reflexões de um Observador Participante. In: Sinais dos Tempos: Diversidade Religiosa no Brasil. Cadernos do ISER 23 (1990): 167-180. GONÇALVES, Ricardo. A trajetória de um budista brasileiro". In: USARSKI, Frank (org.). Budismo no Brasil. São Paulo: Lorosae, 2002, pp.171-192.

HORI, Ichiro. Folk Religion in Japan: Continuity and Change. Chicago: The University of Chicago Press, 1968.

KISALA, Robert. Contemporary Karma: Interpretations of karma in Tenrikyo and Rissho Koseikai, In: Japanese Journal of Religions 21/1(1994), pp.73-91.

LESSER, Jeffrey. A negociação da identidade nacional: Imigrantes, minorias e a luta pela etnicidade no Brasil. São Paulo: Editora da Unesp, 2000.

MIYAO, Sussumu. Os dekassegui como novos transmissores da cultura japonesa”. In: NINOMIYA, Masato (org.). O futuro da comunidade nikkei. São Paulo, Kaleidos, 1996, pp.77-84.

MOL, Hans. Identity and Religion: International, Cross-Cultural Approaches. London: Sage Publications, 1978.

MOL, Hans. The identity model of religion: How it compares with nine other theories of religion and how it might apply to Japan, In: Japanese Journal of Religious Studies, 6/1-2 (1979): 11-38.

MORI, Koichi. Vida Religiosa dos Japoneses e seus Descendentes Residentes no Brasil e Religiōes de Origem Japonesa”. In: Comissão De Elaboração Da História dos 80 Anos da Imigração Japonesa no Brasil (org.). Uma Epopéia Moderna: 80 anos da Imigração Japonesa no Brasil, São Paulo: Hucitec e Sociedade Brasileira de Cultura Japonesa, 1992, pp.559-603. 
MULLINS, Mark. The Life-Cycle of Ethnic Churches in Sociological Perspective. In: Japanese Journal of Religious Studies 14/4 (1987): 321-334.

NAKAMAKI, Hirochika. A Honmon - busuryû-shû no Brasil: através de registros do arcebispo Nissui Ibaragui. In: USARSKI, Frank (org.), O budismo no Brasil. São Paulo, Lorosae, 2002, pp. 73-105.

NUMRICH, Paul David. Old Wisdom in the new world: Americanization in two immigrant Theravada Buddhist temples. Knoxville: The University of Tennessee Press, 1996.

PONTIGNAT, Philippe; STREIFF-FENART, Jocelyne. Teorias da Etnicidade. Seguido de Grupos Étnicos e suas Fronteiras de Fredrik Barth. São Paulo: Editora da Unesp, 1997.

PEREIRA, Ronan Alves: O Budismo Leigo da Associação Brasil Sôka Gakkai Internacional: do Japão para o mundo, dos imigrantes para os brasileiros. In: Frank Usarski (org.). O Budismo no Brasil - Uma Religião entre Tradição e Adoção, São Paulo: Lorosae, pp.253-286.

SAITO, Toshiaki. Brasileiros e Japoneses, confronto de Identidade (o perfil psicológico do nikkei). In: III Convenção Panamericana Nikkei: O Nikkei e sua americanidade. São Paulo: Massao Ohno Editor, 1986, pp.199-212.

SEAGER, Richard. Buddhism in America. New York: Columbia University Press, 1999.

SHOJI, Rafael. Uma Perspectiva Analítica para os Convertidos ao Budismo Japonês no Brasil, In: REVER, Ano 2, n.6 (2002): 85-111.

SHOJI, Rafael. The Failed Prophecy of Shinto Nationalism and the Rise of Japanese Brazilian Catholicism, In: Japanese Journal of Religious Studies, v. 35, (2008): 13-38.

TANAKA, Kenneth. Issues of Ethnicity in the Buddhist Churches of America. In: WILLIAMS, Duncan Ryûken; QUEEN, Christopher S. (eds.). American Buddhism: Methods and Findings in Recent Scholarship. Richmond: Curzon Press, 1999, pp.3-19.

USARSKI, Frank. O Budismo no Brasil - um resumo sistemático In: USARSKI, Frank (org.). $O$ Budismo no Brasil. São Paulo: Lorosae, 2002, pp. 9-33.

USARSKI, Frank. The Last Missionary to Leave the Temple Should Turn Off the Light - Sociological Remarks on the Decline of Japanese Immigrant Buddhism in Brazil, In: Japanese Journal of Religious Studies, v. 35 (2008): 39-59.

YANAGITA, Kunio. About Our Ancestors: The Japanese Family System, New York: Greenwood Press, 1970.

YOO, David. A Religious History of Japanese Americans in California. In: MIN, Pyong Gap; KIM, Jung Ha (eds.). Religions in Asian America: Building Faith Communities. Walnut Creek: Altamira Press, 2002, pp.121-142.

Recebido: 08/04/2011

Aprovado: 31/05/2011 